\title{
Antigenic properties of the SARS-CoV-2 nucleoprotein are altered by the RNA admixture
}

\author{
Denis E Kolesov ${ }^{1}$, Maria V Sinegubova ${ }^{1}$, Irina V Safenkova ${ }^{2}$, Ivan I Vorobiev ${ }^{1}$, Nadezhda A Orlova ${ }^{\text {Corresp. } 1}$ \\ 1 Laboratory of Mammalian Cell Bioengineering, Institute of Bioengineering, Research Center of Biotechnology of the Russian Academy of Sciences, \\ Moscow, Russia \\ 2 Laboratory of Immunobiochemistry, Institute of Biochemistry, Research Center of Biotechnology of the Russian Academy of Sciences, Moscow, Russia, \\ Moscow, Russia \\ Corresponding Author: Nadezhda A Orlova \\ Email address: nobiol@gmail.com
}

Determining the presence of antibodies to the SARS-CoV-2 antigens is the best way to identify infected people, regardless of the development of symptoms of COVID-19. The nucleoprotein (NP) of the SARS-CoV-2 is an immunodominant antigen of the virus - anti-NP antibodies are detected in persons previously infected with the virus with the highest titers. Many test systems for detecting antibodies to SARS-CoV-2 contain NP or its fragments as antigen. The sensitivity and specificity of such test systems differ significantly, which can be explained by variations in the antigenic properties of NP caused by differences in the methods of its cultivation, isolation and purification. We investigated this effect for the E.coli-derived SARS-CoV-2 NP, obtained from the cytoplasm in the soluble form. We hypothesized that co-purified nucleic acids that form a strong complex with NP might negatively affect NP's antigenic properties. Therefore, we have established the NP purification method, which completely eliminates the RNA in the NP preparation. Two stages of RNA removal were used - treatment of the crude lysate of $E$. coli with RNase $A$ and subsequent selective RNA elution with $2 \mathrm{M} \mathrm{NaCl}$ solution. The resulting NP without RNA has a significantly better signal-to-noise ratio when used as an ELISA antigen and tested with a control panel of serum samples with antibodies to SARS-CoV-2; therefore, it is preferable for in vitro diagnostic use. The same increase of the signal-to-noise ratio was detected for the free N-terminal domain of the NP. Complete removal of RNA complexed with NP during purification will significantly improve its antigenic properties, and the absence of RNA in NP preparations should be controlled during the production of this antigen. 
1 Antigenic properties of the SARS-CoV-2 nucleoprotein are 2 altered by the RNA admixture

3 Denis E. Kolesov $^{1}$, Maria V. Sinegubova ${ }^{1}$, Irina V. Safenkova ${ }^{2}$, Ivan I. Vorobiev ${ }^{1}$, Nadezhda

4 A. Orlova*1

5

$6{ }^{1}$ Laboratory of Mammalian Cell Bioengineering, Institute of Bioengineering, Research Center of

7 Biotechnology of the Russian Academy of Sciences. Moscow, Russia.

$8{ }^{2}$ Laboratory of Immunobiochemistry, Institute of Biochemistry, Research Center of

9 Biotechnology of the Russian Academy of Sciences. Moscow, Russia.

10

Corresponding Author:

Nadezhda Orlova ${ }^{1}$

Email address: nobiol@gmail.com

\section{Abstract}

Determining the presence of antibodies to the SARS-CoV-2 antigens is the best way to identify infected people, regardless of the development of symptoms of COVID-19. The nucleoprotein (NP) of the SARS-CoV-2 is an immunodominant antigen of the virus - anti-NP antibodies are detected in persons previously infected with the virus with the highest titers. Many test systems for detecting antibodies to SARS-CoV-2 contain NP or its fragments as antigen. The sensitivity and specificity of such test systems differ significantly, which can be explained by variations in the antigenic properties of NP caused by differences in the methods of its cultivation, isolation and purification. We investigated this effect for the E.coli-derived SARS-CoV-2 NP, obtained from the cytoplasm in the soluble form. We hypothesized that co-purified nucleic acids that form a strong complex with NP might negatively affect NP's antigenic properties. Therefore, we have established the NP purification method, which completely eliminates the RNA in the NP preparation. Two stages of RNA removal were used - treatment of the crude lysate of E. coli with RNase A and subsequent selective RNA elution with $2 \mathrm{M} \mathrm{NaCl}$ solution. The resulting NP without RNA has a significantly better signal-to-noise ratio when used as an ELISA antigen and tested with a control panel of serum samples with antibodies to SARS-CoV-2; therefore, it is preferable for in vitro diagnostic use. The same increase of the signal-to-noise ratio was detected for the free N-terminal domain of the NP. Complete removal of RNA complexed with NP during purification will significantly improve its antigenic properties, and the absence of RNA in NP preparations should be controlled during the production of this antigen.

\section{Introduction}

The coronavirus pandemic affects the life of the entire population of the globe, with 258830438 confirmed cases of COVID-19 for 26.11.2021. The emergence of new SARS-CoV-2 variants(Khan et al., 2021) escaping the immune defense and variants with increased contagiousness and the impossibility of global vaccination of the entire planet population suggest that the pandemic will continue for several more epidemic seasons. 
41 There is still a need for mass and cost-effective production of tests. This problem is especially acute in

42 countries with underdeveloped economies. The widespread availability of serological tests will help

43 defeat the pandemic and return to normalcy.

44 Acute or past infection of the individual with the SARS-CoV-2 virus may be tested using various in vitro

45 diagnostic methods, mainly the RT-PCR or serological testing for viral antigens presence or anti-viral

46 antibodies (Kilic, Weissleder \& Lee, 2020). Testing for anti-SARS-CoV-2 antibodies reliably indicates

47 the presence of anti-viral immunity, regardless of the presence or absence of symptoms of the disease.

48 The generalized data from the population-wide serological studies makes it possible to accurately assess

49 the transmission dynamics and the actual scale of the virus's spread (Dorigatti et al., 2021). During mass

50 vaccination and for quite a long time after it, serological tests will also play a critical role in assessing the

51 effectiveness and duration of the vaccine's action.

52 Potential antigens for SARS-CoV-2 serological tests were evaluated on their specificity against other

53 common human coronaviruses (HCoV-OC43, HCoV-HKU1, HCoV-229E, HcoV-NL63) (Tilocca et al.,

54 2020), (Dobaño et al., 2020) and it was found that among the four viral structural proteins (proteins S, E,

$55 \mathrm{M}, \mathrm{N})$, two most abundant proteins - S and N (NP) are sufficiently specific; they are most often used for

56 practical serological testing. The $\mathrm{N}$-antigen is the most abundant proteinaceous component of the viral

57 particle; therefore, it can be assumed that $\mathrm{N}$-antigen causes the appearance of the highest antibody titers

58 during the infection. Serological tests using the $\mathrm{N}$ antigen are expected to have the best sensitivity.

59 According to (Okba et al., 2020), ELISA with the S1 antigen was more specific in discriminating

60 COVID-19 patients and HCoV or MERS-CoV groups, and ELISA with the NP was more sensitive in

61 revealing the seropositivity of patients with mild COVID-19. In direct comparison, the $\mathrm{S}$ antigen gives

62 slightly higher ELISA values than the NP antigen for the COVID-19 patients(Chen et al., 2020).

63 Most of the approved and used to date SARS-CoV-2 vaccines do not elicit a humoral immune response to

64 NP (Martínez-Flores et al., 2021); therefore, serological tests based on both S and N antigens may help to

65 distinguish between vaccinated and/or people infected with SARS-CoV-2. The specificity and sensitivity

66 of NP-based serological tests should be as high as possible since S-antigen tests cannot be used as a

67 parallel or control method for detecting SARS-CoV-2 infection in a significant proportion of patients.

68 The nucleoprotein of beta coronaviruses (NP) is immunodominant and most abundantly expressed viral

69 protein in the cytoplasm of infected cells (Timani et al., 2004). It consists of two tightly folded domains,

70 N-terminal (NTD) and C-terminal (CTD or N2b), responsible for RNA binding and NP dimerization,

71 respectively, and the surrounding short unstructured regions N1a, N2a, and B / N3. Nucleoprotein is the

72 only cytoplasmic protein of coronaviruses that is purposefully captured by viral particles separating from

73 infected cells. The NP is synthesized in the cell cytoplasm, so it is not glycosylated. It contains a single

74 cluster of Ser/Thr phosphorylation sites in the N2a subdomain (Tugaeva et al., 2021), and, probably,

75 some NP molecules have acetylated Lys residues (Hatakeyama et al., 2021), so the recombinant NP from

76 E. coli will adequately represent the natural NP as the antigen. At the same time, the recombinant NP,

77 produced in mammalian or yeast cells as the secreted protein, contains multiple N-and O-glycan moieties

78 and, presumably, is partially shielded from binding antibodies (Supekar et al., 2020). E. coli derived NP,

79 its single domains, and deletion mutants are widely used in serological assays (Guo et al., 2020)(Yamaoka

80 et al., 2021).

$81 \mathrm{NP}$ is a highly basic protein prone to multimerization and non-specific binding of nucleic acids (Zeng et

82 al., 2020), and both the NTD and CTD contain highly positively charged regions (Chang et al., 2014).

83 Residual admixtures of host cell biopolymers and polymerization state of the NP could significantly

84 change depending on its purification from specific impurities; therefore, it is necessary to develop a

Peer] reviewing PDF | (2021:08:64316:1:1:NEW 1 Dec 2021) 
85 method for obtaining a SARS-CoV-2 NP preparation that provides the maximum efficiency of the

86 serological testing. Many publications (Nasrallah et al., 2021)(Tehrani et al., 2020) mention the highly

87 differing quality of commercially available NP-based tests. Still, they do not discuss specific impurities in

88 the antigen that can cause a decrease in the sensitivity of the tests or methods for specific purification of

89 these impurities (Liu et al., 2021).

90 We proposed that NP's antigenic properties may be significantly altered due to the presence of nucleic

91 acid impurities, which will force the NP to the multimeric state (Perdikari et al., 2020), partially block its

92 surface, and expel some of the NP-binding antibodies by the negatively charged patches. Methods of

93 nucleic acid removal from viral nucleoproteins are well known - treatment with nucleases and

94 dissociation of complexes with the high salt solutions (Damodaran \& Kinsella, 1983). Here the present

95 the simple protocol of SARS-CoV-2 NP expression and purification and demonstrate the change in its

96 antigenic properties upon two-stage removal of nucleic acid contaminants.

97 Materials \& Methods

98 Molecular cloning

99 The NP open reading frame flanked with the PciI-HindIII sites was synthesized by Epoch Life Science,

100 Inc (Missouri City, TX, USA). The synthetic gene was cloned into the pHYP expression vector (Genbank

101 ID: MW187859), cut at the NcoI and HindIII sites. The codon usage of the ORF was optimized for E. coli

102 expression with the GENEius-Light software http://www.geneius.de/GENEius, and a C-terminal 10xHis

103 cluster was added to the ORF for further purification of the target protein by metal chelate

104 chromatography. The resulting expression plasmid, pHYP-NPC-10H (Genbank ID: MW187860,

105 Addgene \#162789), was transformed into the E. coli BL21[DE3] cells.

106 The AvrII and NheI sites were introduced into the synthetic NP ORF using the Silent Mutator online tool

107 (https://www.molbiotools.com/silentmutator.html).

108 The N-terminal part of NP ORF was deleted using the AvrII and NheI restriction of the pHYP-NPC-10H

109 plasmid with subsequent ligation, resulting in the pHYP-NP-tail-C-10H plasmid, the protein coded

110 corresponds to residues 218-419 of the SARS-CoV-2 NP, protein code - CTD.

111 The C-terminal part was deleted using NheI-HindIII restriction of the pHyp-NP plasmid and exchanged to

112 the pair of annealed oligos AD-NPhead-NheF (5'-

113 CTAGCCCATCACCATCATCACCACCATCACCATCACTGATA-3'); AD-NPhead-HindR (5'-

114 AGCTTATCAGTGATGGTGATGGTGGTGATGATGGTGATGGG-3'), resulting in pHYP-NP-head-C-

$11510 \mathrm{H}$ plasmid, the protein coded corresponds to residues 1-220 of the SARS-CoV-2 NP, protein code -

116 NTD. Sequences of the expected proteins are shown in Fig. S1.

117 Bacterial culture

118 Expression plasmids were transformed to the BL21[DE3] cells. The resulting strains were grown in shake

119 flasks in the $2 \mathrm{xYT}$ medium with $30 \mathrm{mg} / \mathrm{L}$ kanamycin and $0.1 \%$ glucose at $37^{\circ} \mathrm{C}$, induced with the $1 \mathrm{mM}$

120 isopropyl- $\beta$-D-thiogalactopyranoside at OD600 0.6-1 AU and cultivated at $30^{\circ} \mathrm{C}$ for $3 \mathrm{~h}$.

121 Bacterial cells were collected by centrifugation, $1 \mathrm{~g}$ of wet cell paste obtained was resuspended in $10 \mathrm{ml}$

122 lysis buffer (20 mM sodium phosphate, $\mathrm{pH} 7.4 ; 10 \mathrm{mM}$ imidazole, $10 \mu \mathrm{g} / \mathrm{ml}$ egg white lysozyme,

$1230.1 \%$ Triton X-100) and incubated 15 min on ice. Bacterial DNA was sheared with two sonication rounds

124 of $20 \mathrm{sec}$ using a Bandelin Sonopuls ultrasonic homogenizer (BANDELIN electronic GmbH \& Co. KG).

125 The bacterial lysates were cleared by centrifugation at $45,000 \times \mathrm{g}$ for $10 \mathrm{~min}$ and then divided into two

126 parts, one of which was treated with $10 \mu \mathrm{g} / \mathrm{ml}$ RNAse A (Thermo Fischer Scientific) for 15 min on ice,

127 and the second one was left untreated (NP-RNA; NTD-RNA).

128 NP and NTD purification

Peer] reviewing PDF | (2021:08:64316:1:1:NEW 1 Dec 2021) 
129 Immobilized metal affinity chromatography was carried out at room temperature on the Akta Explorer 130 system and the Tricorn 5/5 column, packed with $1 \mathrm{ml}$ of Ni-Sepharose resin (all Cytiva). The optical density of the eluate was monitored and recorded using the instrument control software Unicorn (Cytiva). The column was equilibrated with $20 \mathrm{mM}$ sodium phosphate, $\mathrm{pH} 7.5 ; 500 \mathrm{mM} \mathrm{NaCl}, 10 \mathrm{mM}$ imidazole solution. Clarified bacterial lysates were applied to the column at $0.5 \mathrm{ml} / \mathrm{min}$. The column was washed with equilibration solution until a stable baseline at $1 \mathrm{ml} / \mathrm{min}$ flow (approximately 10 column volumes), then with the equilibration solution with $50 \mathrm{mM}$ imidazole at the same flow velocity for 10 column volumes. The column was optionally washed with the equilibration solution with $2 \mathrm{M} \mathrm{NaCl}$ (NP, NP$\mathrm{NaCl}, \mathrm{NTD}, \mathrm{NTD}-\mathrm{NaCl}$ samples) until the stable baseline. Target proteins were eluted with the equilibration solution with $250 \mathrm{mM}$ imidazole- $\mathrm{HCl}$ at $0.5 \mathrm{ml} / \mathrm{min}$; main eluate peaks were collected as single fractions. Ten minutes flow stop was performed during elution for the yield maximization. Purified proteins were divided into aliquots, flash-frozen in liquid nitrogen, and stored frozen for further use. Purified protein solutions were intentionally not desalted from $\mathrm{NaCl}$ and imidazole and used in further experiments, due to rapid precipitation of the NP upon desalting to the PBS solution. Target protein concentration was determined using the Bradford method with the Total protein kit (Sigma, USA). Nucleic acids concentration measurement

The concentration of RNA and DNA in protein samples was measured using the Qubit fluorometer (ThermoFischer Scientific) and Qubit RNA and Qubit DNA HS reagent kits.

\section{SDS-PAGE}

Proteins were analyzed by SDS-PAGE (12.5\% acrylamide) in reducing conditions with the PageRuler prestained marker (ThermoFisher Scientific), $5 \mu \mathrm{l} /$ lane. The gels were stained with colloidal Coomassie blue, de-stained with the deionized water until clear background, scanned using the flatbed scanner in the transparent mode, saved as 16-bit grayscale images. The images were analyzed using the TotalLab TL120 software (Nonlinear Dynamics, UK).

\section{Analytical size-exclusion chromatography}

Size exclusion chromatography was performed according to (Sinegubova et al., 2021) with minor changes. Mobile phase was $20 \mathrm{mM}$ sodium phosphate $\mathrm{pH} 7.5,100 \mathrm{mM}$ imidazole-HCl, $150 \mathrm{mM}$ or $300 \mathrm{mM}$ or $2 \mathrm{M} \mathrm{NaCl}$. Size exclusion chromatography with the multi-angle light scattering (MALS) detection was performed as described in (Tugaeva et al., 2021) with minor changes - mobile phase was $20 \mathrm{mM}$ sodium phosphate $\mathrm{pH}$ 7.5, $100 \mathrm{mM}$ imidazole- $\mathrm{HCl}, 300 \mathrm{mM} \mathrm{NaCl}$, flow $0.5 \mathrm{ml} / \mathrm{min}$, column

159 Superdex 200 10/300 (Cytiva).

160 Dynamic light scattering (DLS)

161

162

163

164

165

166

167

168

169

170

171

172

The hydrodynamic diameter (Dh) of proteins was measured using DLS as described in (Safenkova et al., 2016) with minor changes. Protein concentrations were in the $0.6-1 \mathrm{mg} / \mathrm{ml}$ range for all samples tested, 20 $\mathrm{mM} 20 \mathrm{mM}$ sodium phosphate $\mathrm{pH} 7.5,500 \mathrm{mM} \mathrm{NaCl}, 250 \mathrm{mM}$ imidazole solution in all cases.

\section{Enzyme-linked immunosorbent assay (ELISA)}

Control pooled serum samples with established immunoreactivity in clinically approved tests were obtained from Anti-SARS-CoV-2 Verification Panel for Serology Assays (NIBSC panel, National Institute for Biological Standards and Control, Potters Bar Hertfordshire EN6 3QG, UK). The NIBSC Panel is comprised of 37 samples, 23 positive samples, and 14 negative samples. We also used the samples described in the article (Sinegubova et al., 2021), namely pre-COVID-19 normal human plasma sample (Renam, Moscow, Russia) and control pooled serum samples obtained from patients with the PCR-confirmed SARS-CoV-2 infection (Xema Co., Ltd, Moscow, Russia). All samples were tested in triplicates if not stated otherwise.

Peer] reviewing PDF | (2021:08:64316:1:1:NEW 1 Dec 2021) 
173 Microtiter plate wells (Corning, USA.) were coated with $100 \mu \mathrm{lof} 1 \mu \mathrm{g} / \mathrm{ml}$ test antigen in PBS with 100

$174 \mathrm{mM}$ imidazole solution and incubated overnight at $+4^{\circ} \mathrm{C}$. The wells were washed three times with PBS-

$1750.02 \%$ Tween (PBST) and blocked for $1 \mathrm{~h}$ at $37^{\circ} \mathrm{C}$ with $3 \%$ bovine serum albumin (BSA; Sigma) in PBS,

176 washed with PBST, and used immediately. Test sera were prediluted with 1\% BSA-PBS, applied as serial

177 twofold dilutions in the 1:400-1:25 600 range, and incubated for $1 \mathrm{~h}$ at $37^{\circ} \mathrm{C}$. Wells were washed three

178 times with PBST, secondary anti-human IgG antibody-HRP conjugate (Xema Co., cat. T271X@1702)

179 was used at the 1:20 000 dilution. After $1 \mathrm{~h}$ at $+37^{\circ} \mathrm{C}$, wells were washed five times with the PBST and

$180100 \mu \mathrm{l}$ of ready-to-use TMB solution (Xema Co.) was added to each well. The color was developed for

181 exactly 10 minutes at room temperature $\left(+25 \pm 2^{\circ} \mathrm{C}\right)$. The reaction was stopped by addition of $100 \mu 1$ of $5 \%$

182 orthophosphoric acid per well. Absorbance at $450 \mathrm{~nm}$ was measured with a Multiskan EX plate reader

183 (Thermo Fischer Scientific).

\section{Mass spectrometry}

185 High-performance liquid chromatography-electrospray ionization-mass spectrometry (HPLC-ESI-MS)

186 analysis was performed with the Impact II QqTOF high-resolution mass-spectrometer (Bruker Daltonik,

187 Germany), the UHPLC (Bruker Daltonik), and the Nucleodur C4 300-5 ec 4.6*150 mm column

188 (Macherey-Nagel, Germany). Data acquisition conditions were as follows: flow $1 \mathrm{ml} / \mathrm{min}$, split 1:10,

189 gradient elution from $2 \%$ to $98 \%$ B in $40 \mathrm{~min}$ (A: $0.1 \%$ formic acid in water, B: $0.1 \%$ formic acid in

190 acetonitrile), column temperature $40^{\circ} \mathrm{C}, 30-50 \mu \mathrm{g}$ of sample per injection, ESI source in positive mode,

$191 \mathrm{HV}$ capillary at $4.5 \mathrm{kV}$, spray gas - nitrogen at $1.8 \mathrm{bar}$, dry gas - nitrogen at $8 \mathrm{~L} / \mathrm{min} 220^{\circ} \mathrm{C}$. Spectra were

192 processed with BioPharma Compass 3.1.1 (Bruker Daltonik, Germany).

\section{Statistical analysis}

194 ELISA data were analyzed by the Student's two-tailed unpaired t-test or one-way ANOVA with the post-

195 hoc Tukey-Kramer HSD test utilizing the GraphPad Prism (GraphPad Software, San Diego, CA, USA),

196 LibreOffice (https://www.libreoffice.org/) and the RStudio software (RStudio PBC, Boston, MA, USA).

197 All Student's and ANOVA p-values are presented with the raw OD readings data in the Supporting File.

198 Correlational analysis for ELISA data obtained for the NIBSC panel serum samples was performed for 5

199 semi-quantitative and quantitative assays (published results) and two experimentally performed assays

200 with full-length NP antigen variants. The analysis was performed for all 37 serum samples and the

201 COVID-19 positive sera subset. Pearson's $r$ was calculated using the RStudio software. In the case of

202 Pearson's $r$ 0-0.19 is regarded as very weak, $0.2-0.39$ as weak, $0.40-0.59$ as moderate, $0.6-0.79$ as

203 strong, and $0.8-1$ as very strong correlation. Scripts employed for the correlation analysis are deposited at

204 the GitHub website: https://github.com/d-kolesiko/ELISA.

\section{Results}

206 Expression and purification of the intact NP

207 E. coli strain BL21 [DE3] was transformed with the plasmid pHYP-NPC-10H encoding the full-length

208 NP SARS-CoV-2 with a C-terminal 10xHis tag (Fig. 1 A). During induction at $30^{\circ} \mathrm{C}$, abundant

209 expression of the target protein in a predominantly soluble form was observed (Fig. $1 \mathrm{~B}$ ); therefore,

210 further optimization of the cultivation conditions was not carried out. The target protein was purified from

211 the supernatant of lyzed bacterial cells by the immobilized metal affinity chromatography (Fig. $1 \mathrm{C}$ ).

212 According to UV absorption data, the purified NP contained a significant amount of nucleic acid

213 admixture - 280:260 $\mathrm{nm}$ absorption ratio was 0.514 , far below the expected 1.75 ratio of the pure protein.

214 According to the intercalating dye fluorescence intensity analysis performed with the Qubit fluorimeter

215 (Thermo Fischer Scientific), contaminating nucleic acids were found to be the RNA. RNA:protein mass

216 ratio was $25.0 \%$ for the NP preparation, untreated with the RNAse A (NP-RNA protein sample). Lysis 
217 and purification of the full-length NP were repeated with two additional RNA removal steps - treatment

218 of the crude cell lysate with the $10 \mathrm{mg} / \mathrm{L}$ RNAse A for $15 \mathrm{~min}$ on ice and column wash with the

219 equilibration solution, adjusted to the $2 \mathrm{M} \mathrm{NaCl}$ concentration. According to the chromatography traces

220 data (Fig. $1 \mathrm{D}, \mathrm{E}), 2 \mathrm{M} \mathrm{NaCl}$ solution was sufficient to dissociate the protein - RNA complexes and elute

221 the contaminating RNA. Subsequent elution of the target protein with the $250 \mathrm{mM}$ imidazole solution

222 produced the elution peak with the $280 / 260 \mathrm{~nm}$ absorption ratio of 1.2, typical for the pure protein.

223 Imidazole elution of the target protein without the RNAse A treatment and $2 \mathrm{M} \mathrm{NaCl}$ wash produced a

224 peak with the $280 / 260 \mathrm{~nm}$ absorption ratio of 0.53 , indicating the significant contamination with nucleic

225 acids. This observation is in line with the intercalating dye analysis of NP preparations. The stepwise

226 gradient of the $\mathrm{NaCl}$ concentration in the wash solution revealed that admixtures with the 280:260 nm

227 light adsorption ratio 1:2, typical for the nucleic acid, are eluted mostly with the $1 \mathrm{M}$ and $1.5 \mathrm{M} \mathrm{NaCl}$

228 solutions, making the $2 \mathrm{M} \mathrm{NaCl}$ solution sufficient for the complete removal of nucleic acids from the

229 RNase A - treated NP (Fig. S2).

230 It should be noted that the NP preparation, purified from RNA with both RNAse A treatment and high

231 salt column wash, was completely RNA-free; residual RNA level was below the detection limit of the

232 Quant-iT тм RNA Assay Kit used, i.e., below the $0.05 \%(\mathrm{w} / \mathrm{w})$. According to this measurement, the NP

233 was purified from the RNA at least 12-fold. Both samples of purified NP were tested for the DNA

234 admixture using the Quant-It DNA high sensitivity dye and were found to be DNA-free, residual DNA

235 level was below $12 \mathrm{ppm}$ in both samples. We made two additional control NP preparations - one treated

236 with the RNAse A and not washed on-column with the $2 \mathrm{M} \mathrm{NaCl}$, another - washed with $2 \mathrm{M} \mathrm{NaCl}$ and

237 untreated with the RNAse A, and used these preparations for ELISA. Nucleic acids in the NP preparations

238 visualized on the agarose gel (Fig. $1 \mathrm{~F}$ ) turned out to be highly polymeric.

239 Expression and purification of the NTD and CTD fragments

240 NTD and CTD of the NP in the pHYP plasmid were transformed into the E.coli BL21[DE3] cells.

241 Producers were cultured in the same way as for the full-length NP. We did not detect the protein band

242 corresponding to the CTD upon induction even in the insoluble proteins fraction (Fig. S3). At the same

243 time, free NTD was overexpressed similarly to the full-length NP (Fig. 2 A) and was purified with or

244 without the RNA removal steps as was described above for the full-length NP (Fig. 2 B).

245 NP oligomerization state analysis

246 According to the ESI-MS data, the molecular mass of the purified full-length NP, treated with both RNase

$247 \mathrm{~A}$ and $2 \mathrm{M} \mathrm{NaCl}$ wash, was $46866.94 \mathrm{Da}$, in good agreement with the expected molecular mass of the NP

248 without the N-terminal Met residue; expected average molecular mass 46865.95 Da (Fig. 2 C, Fig. S4).

249 Similar data were obtained for the NTD protein, treated with both RNase A and $2 \mathrm{M} \mathrm{NaCl}$ wash

250 (Fig. 2 D, Fig. S5), molecular mass obtained 24637.52 Da, expected molecular mass 24637.81 Da for the

251 NTD without N-terminal Met. The relative mobility of the NP on the SDS-PAGE corresponds to the

$25252.7 \mathrm{kDa}$, indicating the slight gel retardation typical for the His-tagged protein.

253 The oligomerization state of the full-length NP preparations was checked by the size-exclusion

254 chromatography in physiological (Fig. S6) and high-salt solutions (Fig. 2 E, F, Fig. S6). We observed the

255 anomalous retention time of the target protein on the Superdex-200 column in physiological conditions in

256 the presence and in the absence of contaminating RNA (Fig. S6). In the presence of $300 \mathrm{mM} \mathrm{NaCl}$ in the

257 mobile phase, the RNA-free NP was present mainly in the dimeric form according to the data of MALS

258 detector $-82.4 \mathrm{kDa}$ (Fig. S7 A), but the retention time of the main peak corresponded to the $142 \mathrm{kDa}$ with

259 the minor monomer peak (43.6 kDa) visible (Fig. 2 E). This anomalous behavior of the SARS-CoV-2 NP

260 was already described in other studies (Tugaeva et al., 2021) and may correspond to the complex shape of

Peer] reviewing PDF | (2021:08:64316:1:1:NEW 1 Dec 2021) 
261

262

263

264

265

266

267

268

269

270

271

272

273

274

275

276

277

278

279

280

281

282

283

284

285

286

287

288

289

290

291

292

293

294

295

296

297

298

299

300

301

302

303

304

the NP dimer. At the same time, the NP-RNA produced multiple minor peaks corresponding to various oligomerization numbers, and the major peak was heavily retarded on the column and was not suitable for molecular mass calculation using the direct MALS detection or retention time curve interpolation

(Fig. 2 F). Further increase in the ionic strength of the mobile phase to $2 \mathrm{M} \mathrm{NaCl}$ resulted in the retardation of the major peaks for both NP samples due to the hydrophobic interaction of the NP and the chromatography sorbent (Fig.S6 E, F). NTD protein, unlike the full-length NP, was present mostly in the monomeric form, according to both MALS data and calibration curve interpolation (Fig S7 B, S10) in the physiological conditions and in the presence of $300 \mathrm{mM} \mathrm{NaCl}$ (Fig. S10 A-D). Similar, but not the same, resin retardation results were obtained for the NTD fragment - in the presence of $2 \mathrm{M} \mathrm{NaCl}$ the RNA-free NTD was seen as multiple retarded peaks, including the normal monomeric form, and in the presence of RNA only the retarded forms and small quantities of non-retarded highly polymeric form of the NTD were seen; monomeric NTD is completely absent on the chromatography trace (Fig. S10 E, F).

The SEC analysis of NP and NTD variants shows that both proteins form various multimeric complexes, apparently interacting with the chromatography resin at all $\mathrm{NaCl}$ concentrations used, so all protein samples, including the partially purified NP and NTD variants, were subjected to the dynamic light scattering analysis in solution.

Both completely purified NP and NTD proteins contained a mixture of small and large protein particles. Nucleoprotein molecules were distributed nearly equally between $18 \mathrm{~nm}$ particles (radius corresponds to the dimeric form) and large particles with $\mathrm{D}_{\mathrm{h}}>1000 \mathrm{~nm}$ (Fig. S8 A, B), and most of the NTD molecules are present in the presumably monomeric form, $\mathrm{D}_{\mathrm{h}} 9.2 \mathrm{~nm}$ (Fig. S9 A, B). Ribonuclease A treatment without the on-column $2 \mathrm{M} \mathrm{NaCl}$ wash was sufficient to remove the intermediate particles in the case of $\mathrm{NP}$ protein; particle median sizes and mass distribution are very close for NP and NP RNase+, NaClpreparations (Fig S8 C, D). At the same time, the NTD monomer was not seen after RNase A treatment, most NTD molecules remained in the highly aggregated form. Sodium chloride wash without the RNase A treatment was also insufficient for generating small protein particles in the concentrated NP or NTD solutions (Fig S8 E, F; S9 E, F).

For the NP-RNA preparation that had not undergone RNase or $2 \mathrm{M} \mathrm{NaCl}$ treatments, only large particles were observed, forming the dominant population of particles with $\mathrm{D}_{\mathrm{h}}>1000 \mathrm{~nm}$ (Fig. S8 G, H) and a high $\%$ polydispersity (\%Pd), equal to $70.4 \%$. Oligomeric particles are not seen in this population at all. The NTD-RNA protein sample also was found to contain mainly highly polymeric protein particles, with $\mathrm{D}_{\mathrm{h}}$ $>1000 \mathrm{~nm}$ and \%Pd 8.4, but there was a peak with an average particle size of $77 \mathrm{~nm}$ (\%Pd $5.7 \%$ ) (Fig. S9 $\mathrm{G}, \mathrm{H})$. These results confirmed that only a combination of RNase A treatment and on-column $2 \mathrm{M} \mathrm{NaCl}$ wash is sufficient for depolymerization of the NP, which should maximize the surface accessibility for binding with antibodies.

Oligomerization of the E. coli-derived NP from the closely related beta-coronaviruses SARS-CoV and MERS-CoV has been previously investigated in several works: (He et al., 2004)(Cong et al., 2017), and it was found that NP tends to change the oligomerization state in the presence of nucleic acids. Salt effects on the SARS-CoV-2 NP polymerization were not studied before, but for the unrelated DNA-binding protein of the herpesvirus VP19C, the formation of the protein-DNA complex and the subsequent polymerization are inhibited by increase of the $\mathrm{NaCl}$ concentration to $1 \mathrm{M}$ (Bera et al., 2014). Although a complete understanding of the mechanism of interaction of nucleoprotein monomers with each other has not been achieved, most of the data indicate that NP exists in the form of a multimer in the presence of nucleic acid and in the dimeric form after extensive purification (Perdikari et al., 2020).

\section{ELISA}

PeerJ reviewing PDF | (2021:08:64316:1:1:NEW 1 Dec 2021) 
305 Full-length NP preparations and NTD preparations were used as the immobilized antigen in the antibody 306 capture ELISA testing of the anti-SARS-CoV-2 antibody titers. Proteins were applied to the microplates 307 in exactly equal amounts; the protein concentration was determined in all cases using the Bradford

308 method, which is insensitive to the RNA admixture. Dose-response curves were obtained for positive and 309 negative pooled serum samples, and it can be clearly seen that RNA-free NP antigen gives a significantly 310 (Student's one-tailed paired t-test, all ELISA data analyzed using this test, if not stated otherwise) higher 311 signal at various dilutions of the COVID-19-positive pooled sera (Fig. 3 A).

312 A similar effect was retained for the NTD antigen (Fig. 3 B). At the same time, the pooled pre-COVID-19 313 sera, derived in-house from the lyophilized normal blood plasma, was significantly more reactive with the 314 RNA-complexed full-length NP (Fig. 3 C) than with the pure NP protein. The non-specific binding of the

315

316

317

318

319

320

321

322

323

324

325

326

327

328

329

330

331

332

333

334

335

336

337

338

339

340

341

342

343

344

345

346

347

348 antibodies in the pre-COVID pooled sera to the NTD antigen was very similar for pure NTD and NTDRNA. However, the NTD gave a much weaker ELISA signal than the full-length NP for the COVID-19positive pooled sera, resulting in a lower overall signal-to-noise ratio, determined as 10,9 for the NP and 8,9 for the NTD (Fig S11 F, S12 E). Further analysis was carried out for the full-length NP as the more sensitive and specific antigen.

We also tested all partially purified NP and NTD preparations - treated with the RNase A alone or with $2 \mathrm{M} \mathrm{NaCl}$ column wash alone (Fig. S11, Fig. S12). Expectedly, partial antigen purification resulted in diminished assay signal-to-noise ratios in both cases, mainly due to lower antibody binding to the RNAcomplexed antigens for the pooled PCR + sera.

ELISA testing of the pure NP and NP-RNA antigen was performed for all serum samples from the NIBSC control COVID-19 sera panel, tested at two dilutions - 1:400 and 1:1600 (Fig. 3 D, E) (p=0.008 and $\mathrm{p}=0.03$ respectively, Welch Two Sample t-test, RStudio). Positivity indices were calculated as the ratio of the optical density for the test sample and the mean optical density in negative samples wells plus three times the standard deviation, according to the (Lardeux, Torrico \& Aliaga, 2016) (OD/CO ratio). For both dilutions tested, the statistically significant difference of the $\mathrm{OD} / \mathrm{CO}$ ratio was detected for the positive samples group - RNA-free NP antigen was significantly more reactive with antibodies from positive samples. At the same time, the $\mathrm{OD} / \mathrm{CO}$ ratio for negative samples was very similar for both sera dilutions tested.

We tested the correlation of the OD/CO ratios obtained for NIBSC control panel, pure NP antigen, NPRNA antigen, and published signal strengths for several clinically approved serological tests (Supporting Table 1). All datasets were strongly correlated with the Pearson's $r>0.8$ (Fig. 4 B) (P-values are approximated using the $\mathrm{t}$ or $\mathrm{F}$ distributions). Correlation analysis was performed again for the positive subset of the NIBSC control panel, and it was found that both pure NP and NP-RNA antigens still produce highly correlated results, Pearson's $r>0.8$. At the same time, correlation of OD/CO for our test results with the quantitative and semiquantitative results of few clinically approved test systems was lower, $0.4<\mathrm{r}<0.8$, and correlation of experimentally obtained ELISA data and published data for S antigen and its fragments was approximately the same to the correlation of experimentally obtained data and NP-based approved tests data (Fig. 4 A) (P-values are approximated using the $\mathrm{t}$ or $\mathrm{F}$ distributions). Generally, the correlation of quantitative results of various tests for positive samples from the NIBSC control panel gives the Pearson's $r$ in the $0.4-0.8$ range. Similar Pearson's $r$ values were found for three various automated serological tests in the case of real-world datasets - serum samples from the Qatar population (Nasrallah et al., 2021).

Thus, the RNA-free SARS-CoV-2 NP obtained as described in this article is expected to be more suitable for serological assays than the conventionally purified NP containing the tightly bound RNA. Two 
different techniques of RNA removal should be performed; neither alone is sufficient for the complete purification of the NP antigen.

\section{Discussion}

It is generally believed that NP and S-protein of the SARS-CoV-2 are the most specific antigens for serological testing. In some studies, the NP is claimed as the more specific antigen (Turbett et al., 2021), other studies challenge the specificity of the NP-based automated assays by the cross-antigen testing of the samples with borderline anti-NP signals (Rosadas et al., 2020) or by the direct comparative testing of the NP-based and S-protein RBD-based assays (Zonneveld et al., 2021). Testing large amounts of serum samples with both NP and S antigens allows decreasing the proportion of false determinations to less than $1 \%$ (Poljak et al., 2021).

A significant proportion of the approved anti-SARS-CoV-2 vaccines codes or contains only the S-protein, so the vaccinated individuals are expected to be S-protein positive regardless of the COVID-19 disease. If infected with the SARS-CoV-2, such individuals may still be reliably screened using the NP-based serological tests. Although the general method of obtaining the recombinant beta-coronavirus NP is well known (Timani et al., 2004), and the presence of the RNA admixture in the NP was also described previously (Liu et al., 2021), alteration of its antigenic properties caused by the RNA impurity was not reported yet. We have demonstrated that the NP as the ELISA antigen dramatically loses its immunoreactivity upon binding the bacteria-derived RNA.

We have shown that the antigenic properties of the SARS-CoV-2 nucleoprotein change significantly upon the complete removal of the associated RNA. In ELISA tests with the RNA-free NP antigen, we observed a statistically significant increase in the observed positivity indices for control positive sera and virtually no change in the nonspecific antigen binding for the negative control sera.

When testing a pooled serum sample obtained from PCR-confirmed patients and a pre-COVID-19 pooled serum sample, it was also found that completely RNA-free NP is significantly less immunoreactive against a known negative sample than NP with an admixture of RNA.

The change of the antigenic properties of NP also reproduced for its free N-terminal domain. Thus, the partial loss of the antigenic properties of the RNA-bound NP cannot be explained by the rearrangement of NP into multimeric complexes alone. Apparently, a significant part of the NP's surface is blocked by nucleic acids from contact with antibodies. It can also be assumed that the actual level of extracellular RNA in the studied serum samples might also influence the observed titer of antibodies to NP SARSCoV-2; a more detailed study of this issue may be the subject of further research.

\section{Conclusions}

We have demonstrated the importance of specific purification of NP preparations for serodiagnostic testing from co-purified nucleic acids and identified one of the possible causes for the variation in the results of different serological tests. We have developed a purification procedure that includes only the linearly scalable operations and may be used without major changes to produce the desired quantities of NP, suitable for serological testing. We believe that the imperfect specificity of NP-based serological tests for SARS-CoV-2 could be associated with insufficient antigen purification from RNA. The specific removal of nucleic acids during NP production would improve the selectivity of new and existing serological tests.

\section{Acknowledgements}


392 We thank Alexander Ivanov (Institute of Molecular biology Russian Academy of Sciences, 393 Moscow, Russia) and Valentin Manuvera (Research Institute for Physico-Chemical Medicine, 394 Moscow, Russia) for valuable comments and discussions on NP properties; Dr. Yuri Lebedin, 395 Eugenia Kostrikina, and Xema Co., Ltd., Moscow, Russia for providing control sera samples.

396 We thank Nikolay N. Sluchanko (A.N. Bach Institute of Biochemistry, Federal Research Center 397 of Biotechnology of the Russian Academy of Sciences, Moscow, Russia) for the size-exclusion 398 chromatography with MALS detection analysis and valuable comments on the NP behavior in 399 solutions; Andrey M. Tsedilin (Institute of Biochemistry) for the ESI-MS analysis.

400 The measurements were carried out in the Shared-Access Equipment Centre "Industrial

401 Biotechnology" of the Research Center of Biotechnology of the Russian Academy of Sciences. 402 DNA sequencing was carried out in the inter-institutional Center for collective use "GENOME" 403 IMB RAS, organized with the support of the Russian Foundation of Basic Research.

404 The study was supported by the Russian Foundation for Basic Research (grant 20-58-55001) and 405 the Ministry of Science and Higher Education of the Russian Federation.

406

407

408

409

410

411

412

413

414

415

416

417

418

419

420

421

422

423

424

425

426

427

428

429

430

431

432

\section{References}

Rosadas C, Randell P, Khan M, McClure MO, Tedder RS. 2020. Testing for responses to the wrong SARS-CoV-2 antigen? The Lancet 396:e23. DOI: 10.1016/S0140-6736(20)31830-4.

Chang CK, Hou MH, Chang CF, Hsiao CD, Huang TH. 2014. The SARS coronavirus nucleocapsid protein - Forms and functions. Antiviral Research 103:39-50. DOI: 10.1016/J.ANTIVIRAL.2013.12.009.

Cong Y, Kriegenburg F, Haan CAM de, Reggiori F. 2017. Coronavirus nucleocapsid proteins assemble constitutively in high molecular oligomers. Scientific Reports 2017 7:1 7:1-10. DOI: 10.1038/s41598-017-06062-w.

Hatakeyama D, Masuda T, Miki R, Ohtsuki S, Kuzuhara T. 2021. In-vitro acetylation of SARSCoV and SARS-CoV-2 nucleocapsid proteins by human PCAF and GCN5. Biochemical and Biophysical Research Communications 557:273-279. DOI: 10.1016/j.bbrc.2021.03.173.

Dobaño C, Santano R, Jiménez A, Vidal M, Chi J, Melero NR, Popovic M, López-Aladid R, Fernández-Barat L, Tortajada M, Carmona-Torre F, Reina G, Torres A, Mayor A, Carolis C, GarcíaBasteiro AL, Aguilar R, Moncunill G, Izquierdo L. 2020. Immunogenicity and crossreactivity of antibodies to SARS-CoV-2 nucleocapsid protein. medRxiv:2020.12.19.20248551. DOI: 10.1101/2020.12.19.20248551.

Nasrallah GK, Dargham SR, Shurrab F, Al-Sadeq DW, Al-Jighefee H, Chemaitelly H, al Kanaani Z, al Khal A, al Kuwari E, Coyle P, Jeremijenko A, Kaleeckal AH, Latif AN, Shaik RM, Rahim HFA, Yassine HM, al Kuwari MG, Qotba H, al Romaihi HE, Tang P, Bertollini R, Al-Thani MH, Althani AA, Abu-Raddad LJ. 2021. Analytic comparison between three high-throughput commercial SARS-CoV-2 antibody assays reveals minor discrepancies in a high-incidence population. Scientific Reports 11. DOI: 10.1038/s41598-021-91235-x.

Timani KA, Ye L, Ye L, Zhu Y, Wu Z, Gong Z. 2004. Cloning, sequencing, expression, and purification of SARS-associated coronavirus nucleocapsid protein for serodiagnosis of SARS. Journal of Clinical Virology 30:309-312. DOI: 10.1016/j.jcv.2004.01.001. 
433

434

435

436

437

438

439

440

441

442

443

444

445

446

447

448

449

450

451

452

453

454

455

456

457

458

459

460

461

462

463

464

465

466

467

468

469

470

471

472

473

474

475

476

Tugaeva K v., Hawkins DEDP, Smith JLR, Bayfield OW, Ker DS, Sysoev AA, Klychnikov OI, Antson AA, Sluchanko NN. 2021. The Mechanism of SARS-CoV-2 Nucleocapsid Protein Recognition by the Human 14-3-3 Proteins :SARS-CoV-2 N association with host 14-3-3 proteins. Journal of Molecular Biology 433. DOI: 10.1016/j.jmb.2021.166875.

Guo L, Ren L, Yang S, Xiao M, Chang D, Yang F, dela Cruz CS, Wang Y, Wu C, Xiao Y, Zhang L, Han L, Dang S, Xu Y, Yang QW, Xu SY, Zhu HD, Xu YC, Jin Q, Sharma L, Wang L, Wang J. 2020. Profiling early humoral response to diagnose novel coronavirus disease (COVID-19). Clinical Infectious Diseases 71:778-785. DOI: 10.1093/cid/ciaa310.

Lardeux F, Torrico G, Aliaga C. 2016. Calculation of the ELISA's cut-off based on the changepoint analysis method for detection of Trypanosoma cruzi infection in Bolivian dogs in the absence of controls. Memórias do Instituto Oswaldo Cruz 111:501. DOI: 10.1590/0074-02760160119.

Liu P, Zong Y, Jiang S, Jiao Y, Yu X. 2021. Development of a Nucleocapsid Protein-Based ELISA for Detection of Human IgM and IgG Antibodies to SARS-CoV-2. ACS Omega 6:9667-9671. DOI: 10.1021/ACSOMEGA.1C00253.

Poljak M, Oštrbenk Valenčak A, Štamol T, Seme K. 2021. Head-to-head comparison of two rapid high-throughput automated electrochemiluminescence immunoassays targeting total antibodies to the SARS-CoV-2 nucleoprotein and spike protein receptor binding domain. Journal of Clinical Virology 137. DOI: $10.1016 /$ j.jcv.2021.104784.

Okba NMA, Müller MA, Li W, Wang C, GeurtsvanKessel CH, Corman VM, Lamers mM, Sikkema RS, Bruin E de, Chandler FD, Yazdanpanah Y, Hingrat Q le, Descamps D, Houhou-Fidouh N, Reusken CBEM, Bosch B-J, Drosten C, Koopmans MPG, Haagmans BL. 2020. Severe Acute Respiratory Syndrome Coronavirus 2-Specific Antibody Responses in Coronavirus Disease Patients - Volume 26, Number 7-July 2020 - Emerging Infectious Diseases journal - CDC. Emerging Infectious Diseases 26:1478-1488. DOI: 10.3201/EID2607.200841.

Perdikari TM, Murthy AC, Ryan VH, Watters S, Naik MT, Fawzi NL. 2020. SARS-CoV-2 nucleocapsid protein phase-separates with RNA and with human hnRNPs. The EMBO Journal 39:e106478. DOI: 10.15252/EMBJ.2020106478.

He R, Dobie F, Ballantine M, Leeson A, Li Y, Bastien N, Cutts T, Andonov A, Cao J, Booth TF, Plummer FA, Tyler S, Baker L, Li X. 2004. Analysis of multimerization of the SARS coronavirus nucleocapsid protein. Biochemical and Biophysical Research Communications 316:476-483. DOI: 10.1016/j.bbrc.2004.02.074.

Zonneveld R, Jurriaans S, van Gool T, Hofstra JJ, Hekker TAM, Defoer P, Broekhuizen-van Haaften PE, Wentink-Bonnema EM, Boonkamp L, Teunissen CE, Heijboer AC, Martens F, de Bree G, van Vugt M, van Houdt R, van Agtmael M, Algera AG, van Baarle F, Bax D, Beudel M, Bogaard HJ, Bomers M, Bos L, Botta M, de Brabander J, Brouwer MC, de Bruin S, Bugiani M, Bulle E, Chouchane O, Cloherty A, Elbers P, Fleuren L, Geerlings S, Geerts B, Geijtenbeek T, Girbes A, Goorhuis A, Grobusch MP, Hafkamp F, Hagens L, Hamann J, Harris V, Hemke R, Hermans SM, Heunks L, Hollmann MW, Horn J, Hovius JW, Koning R, van Mourik N, Nellen J, Paulus F, Peters E, van der Poll T, Preckel B, Prins JM, Raasveld J, Reijnders T, Schinkel M, Schultz MJ, Schuurman A, Sigaloff K, Smit M, Stijnis CS, Stilma W, Thoral P, Tsonas A, van der Valk M, Veelo D, Vlaar APJ, de Vries H, Wiersinga WJ, Wouters D, Zwinderman AH, van de Beek D. 2021. Head-to-head validation of six immunoassays for SARS-CoV-2 in hospitalized patients. Journal of Clinical Virology 139. DOI: 10.1016/j.jcv.2021.104821.

Turbett SE, Anahtar M, Dighe AS, Beltran WG, Miller T, Scott H, Durbin SM, Bharadwaj M, Thomas J, Gogakos TS, Astudillo M, Lennerz J, Rosenberg ES, Branda JA. 2021. Evaluation of three

PeerJ reviewing PDF | (2021:08:64316:1:1:NEW 1 Dec 2021) 
477

478

479

480

481

482

483

484

485

486

487

488

489

490

491

492

493

494

495

496

497

498

499

500

501

502

503

504

505

506

507

508

509

510

511

512

513

514

515

516

517

518

519

520

521

522

523

commercial SARS-CoV-2 serologic assays and their performance in two-test algorithms. Journal of Clinical Microbiology 59. DOI: 10.1128/JCM.01892-20.

Sinegubova MV., Orlova NA, Kovnir SV., Dayanova LK, Vorobiev II. 2021. High-level expression of the monomeric SARS-CoV-2 S protein RBD 320-537 in stably transfected CHO cells by the EEF1A1based plasmid vector. PLOS ONE 16:e0242890. DOI: 10.1371/JOURNAL.PONE.0242890.

Supekar NT, Shajahan A, Gleinich AS, Rouhani D, Heiss C, Azadi P. 2020. SARS-CoV-2 Nucleocapsid protein is decorated with multiple N- and O-glycans. bioRxiv:2020.08.26.269043. DOI: 10.1101/2020.08.26.269043.

Kilic T, Weissleder R, Lee H. 2020. Molecular and Immunological Diagnostic Tests of COVID-19: Current Status and Challenges. iScience 23. DOI: 10.1016/j.isci.2020.101406.

Tilocca B, Soggiu A, Sanguinetti M, Musella V, Britti D, Bonizzi L, Urbani A, Roncada P. 2020. Comparative computational analysis of SARS-CoV-2 nucleocapsid protein epitopes in taxonomically related coronaviruses. Microbes and Infection 22:188-194. DOI: 10.1016/J.MICINF.2020.04.002.

Perdikari TM, Murthy AC, Ryan VH, Watters S, Naik MT, Fawzi NL. 2020. SARS-CoV-2 nucleocapsid protein phase-separates with RNA and with human hnRNPs. The EMBO Journal 39. DOI: 10.15252/embj.2020106478.

Yamaoka Y, Jeremiah SS, Miyakawa K, Saji R, Nishii M, Takeuchi I, Ryo A. 2021. Whole Nucleocapsid Protein of Severe Acute Respiratory Syndrome Coronavirus 2 May Cause False-Positive Results in Serological Assays. Clinical infectious diseases : an official publication of the Infectious Diseases Society of America 72:1291-1292. DOI: 10.1093/cid/ciaa637.

Zeng W, Liu G, Ma H, Zhao D, Yang Y, Liu M, Mohammed A, Zhao C, Yang Y, Xie J, Ding C, Ma X, Weng J, Gao Y, He H, Jin T. 2020. Biochemical characterization of SARS-CoV-2 nucleocapsid protein. Biochemical and Biophysical Research Communications 527:618-623. DOI:

10.1016/J.BBRC.2020.04.136.

Bera A, Perkins EM, Zhu J, Zhu H, Desai P. 2014. DNA Binding and Condensation Properties of the Herpes Simplex Virus Type 1 Triplex Protein VP19C. PLOS ONE 9:e104640. DOI: 10.1371/JOURNAL.PONE.0104640.

Chen Y, Tong X, Li Y, Gu B, Yan J, Liu Y, Shen H, Huang R, Wu C. 2020. A comprehensive, longitudinal analysis of humoral responses specific to four recombinant antigens of SARS-CoV-2 in severe and non-severe COVID-19 patients. PLOS Pathogens 16:e1008796. DOI: 10.1371/JOURNAL.PPAT.1008796.

Damodaran S, Kinsella JE. 1983. Dissociation of nucleoprotein complexes by chaotropic salts. FEBS Letters 158:53-57. DOI: 10.1016/0014-5793(83)80675-9.

Dorigatti I, Lavezzo E, Manuto L, Ciavarella C, Pacenti M, Boldrin C, Cattai M, Saluzzo F, Franchin E, Del Vecchio C, Caldart F, Castelli G, Nicoletti M, Nieddu E, Salvadoretti E, Labella B, Fava L, Guglielmo S, Fascina M, Grazioli M, Alvisi G, Vanuzzo MC, Zupo T, Calandrin R, Lisi V, Rossi L, Castagliuolo I, Merigliano S, Unwin HJT, Plebani M, Padoan A, Brazzale AR, Toppo S, Ferguson NM, Donnelly CA, Crisanti A. 2021. SARS-CoV-2 antibody dynamics and transmission from community-wide serological testing in the Italian municipality of Vo'. Nature Communications 2021 12:1 12:1-11. DOI: 10.1038/s41467-021-24622-7.

Khan A, Khan T, Ali S, Aftab S, Wang Y, Qiankun W, Khan M, Suleman M, Ali S, Heng W, Ali SS, Wei DQ, Mohammad A. 2021. SARS-CoV-2 new variants: Characteristic features and impact on the efficacy of different vaccines. Biomedicine \& pharmacotherapy $=$ Biomedecine \& pharmacotherapie 143. DOI: 10.1016/J.BIOPHA.2021.112176.

Liu PP, Zong Y, Jiang SP, Jiao YJ, Yu XJ. 2021. Development of a Nucleocapsid Protein-Based ELISA for Detection of Human IgM and IgG Antibodies to SARS-CoV-2. ACS omega 6:9667-9671. DOI: 10.1021/ACSOMEGA.1C00253. 
524

525

526

527

528

529

530

531

532

533

534

535

536

537

538

539

540

541

542

543

544

545

546

Martínez-Flores D, Zepeda-Cervantes J, Cruz-Reséndiz A, Aguirre-Sampieri S, Sampieri A, Vaca L. 2021. SARS-CoV-2 Vaccines Based on the Spike Glycoprotein and Implications of New Viral Variants. Frontiers in Immunology 12:2774. DOI: 10.3389/FIMMU.2021.701501/BIBTEX.

Nasrallah GK, Dargham SR, Shurrab F, Al-Sadeq DW, Al-Jighefee H, Chemaitelly H, Al Kanaani Z, Al Khal A, Al Kuwari E, Coyle P, Jeremijenko A, Kaleeckal AH, Latif AN, Shaik RM, Rahim HFA, Yassine HM, Al Kuwari MG, Qotba H, Al Romaihi HE, Tang P, Bertollini R, Al-Thani MH, Althani AA, Abu-Raddad LJ. 2021. Analytic comparison between three high-throughput commercial SARS-CoV-2 antibody assays reveals minor discrepancies in a high-incidence population. Scientific Reports 11. DOI: 10.1038/s41598-021-91235-X.

Safenkova I V., Slutskaya ES, Panferov VG, Zherdev A V., Dzantiev BB. 2016. Complex analysis of concentrated antibody-gold nanoparticle conjugates' mixtures using asymmetric flow field-flow fractionation. Journal of Chromatography A 1477:56-63. DOI: 10.1016/J.CHROMA.2016.11.040.

Tehrani ZR, Saadat S, Saleh E, Ouyang X, Constantine N, DeVico AL, Harris AD, Lewis GK, Kottilil S, Sajadi MM. 2020. Performance of nucleocapsid and spike-based SARS-CoV-2 serologic assays. PLOS ONE 15:e0237828. DOI: 10.1371/JOURNAL.PONE.0237828.

Timani KA, Ye L, Ye L, Zhu Y, Wu Z, Gong Z. 2004. Cloning, sequencing, expression, and purification of SARS-associated coronavirus nucleocapsid protein for serodiagnosis of SARS. Journal of Clinical Virology 30:309-312. DOI: 10.1016/J.JCV.2004.01.001.

Tugaeva K V., Hawkins DEDP, Smith JLR, Bayfield OW, Ker DS, Sysoev AA, Klychnikov OI, Antson AA, Sluchanko NN. 2021. The Mechanism of SARS-CoV-2 Nucleocapsid Protein Recognition by the Human 14-3-3 Proteins :SARS-CoV-2 N association with host 14-3-3 proteins. Journal of Molecular Biology 433. DOI: 10.1016/j.jmb.2021.166875. 


\section{Figure 1}

Expression and purification of the full-length SARS-CoV-2 nucleoprotein.

(A) - Map of the pHYP-NPC-10H plasmid. 10xHIS - C-terminal decahistidine tag; KanR2 kanamycin A resistance gene; HS - hok/sok post-segregation killing locus; lac I - gene of the Lacl repressor protein; T7 prom - promoter for bacteriophage T7 RNA polymerase. (B) - SDSPAGE analysis of the full-length NP expression. Induction with 1 mM IPTG. (C) - SDS-PAGE analysis of the NP purification in the presence or absence of the RNase A. Target protein position is marked with the red arrow. "Non-binding" - column flowthrough fraction. (D), (E) IMAC chromatography traces for the NP purification in the presence or absence of RNase A treatment and $2 \mathrm{M} \mathrm{NaCl}$ solution wash. Eluate absorbance at $280 \mathrm{~nm}$ is in blue, absorbance at $260 \mathrm{~nm}$ - in red. (F) - agarose gel analysis of purified proteins, ethidium bromide staining, double-strand DNA marker. 
A

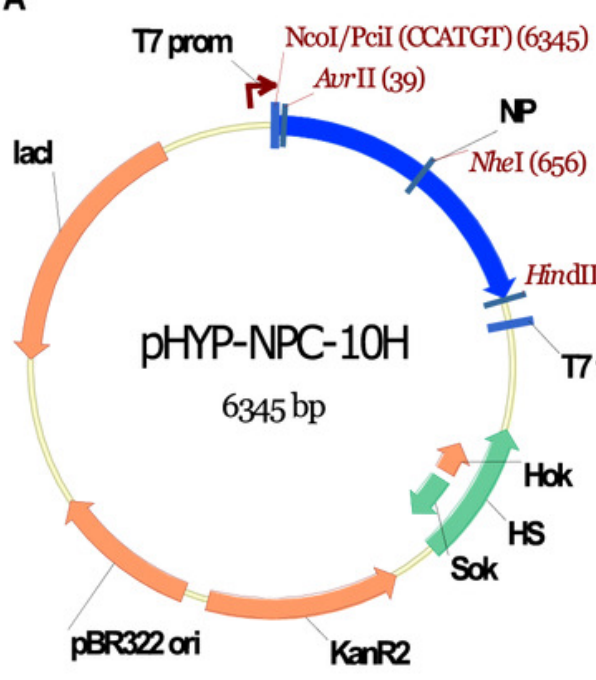

B

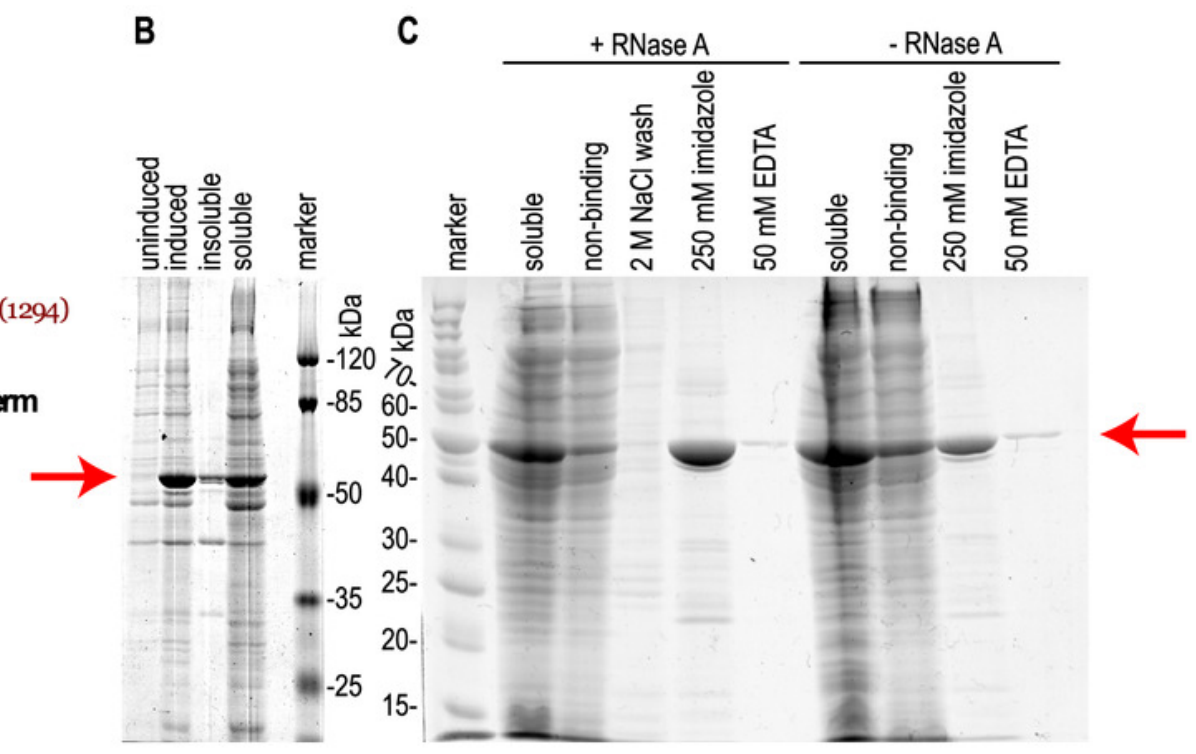

E

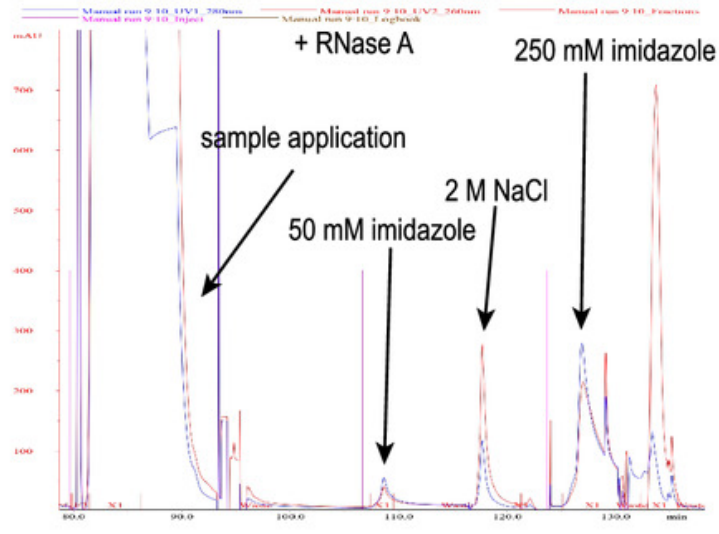

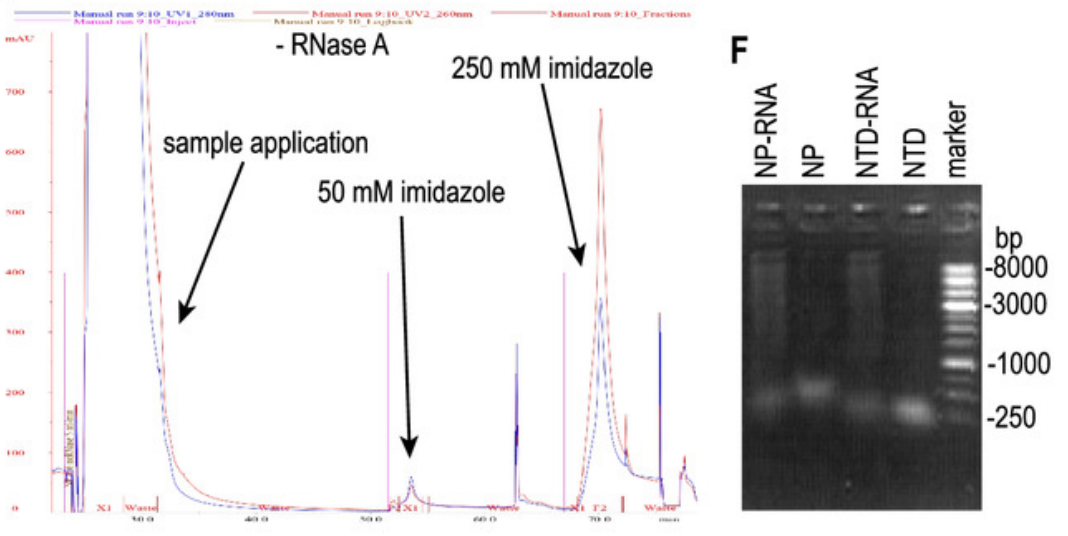




\section{Figure 2}

Expression and purification of the $\mathrm{N}$-terminal domain of the nucleoprotein, analysis of the full-length NP and NTD.

(A) - SDS-PAGE analysis of the NTD expression, induction with 1 mM IPTG. (B) -SDS-PAGE analysis of the NTD during the purification with the RNase A treatment. Target protein position is marked with the red arrow. (C), (D) - ESI-MS mass spectra of the full-length NP and NTD. (E), (F) - Size-exclusion chromatography traces of the pure NP and NP-RNA, absorbance detection at $280 \mathrm{~nm}$ (red) and $260 \mathrm{~nm}$ (blue). Mobile phase $500 \mathrm{mM} \mathrm{NaCl}, 20 \mathrm{mM}$ sodium phosphate, $100 \mathrm{mM}$ imidazole. The protein molecular mass in the main peak was determined by the MALS detector (left value) and calculated from the calibration curve (right value), the molecular mass of the right peak was calculated from the calibration curve.

A

$\mathrm{E}$

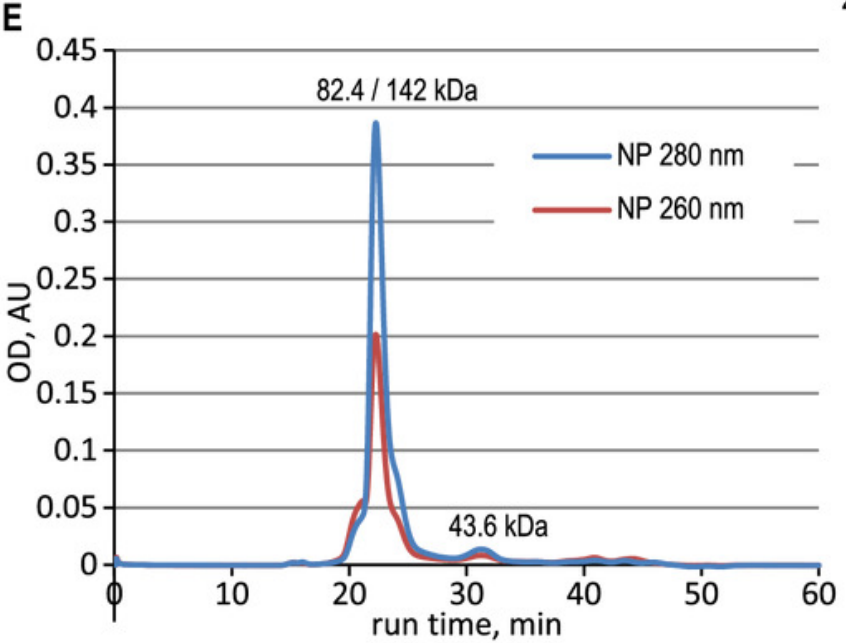

B

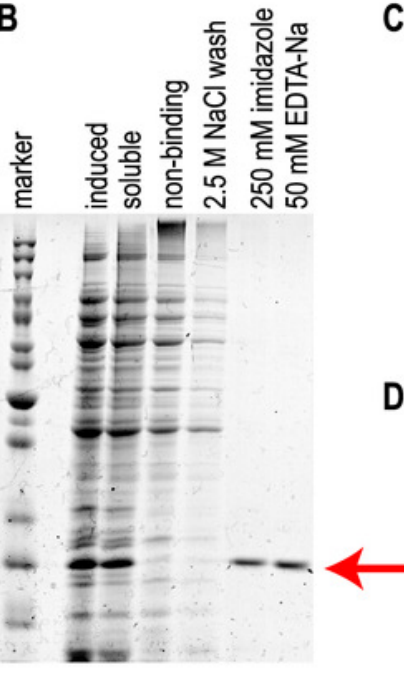

C $\times 10^{5}$
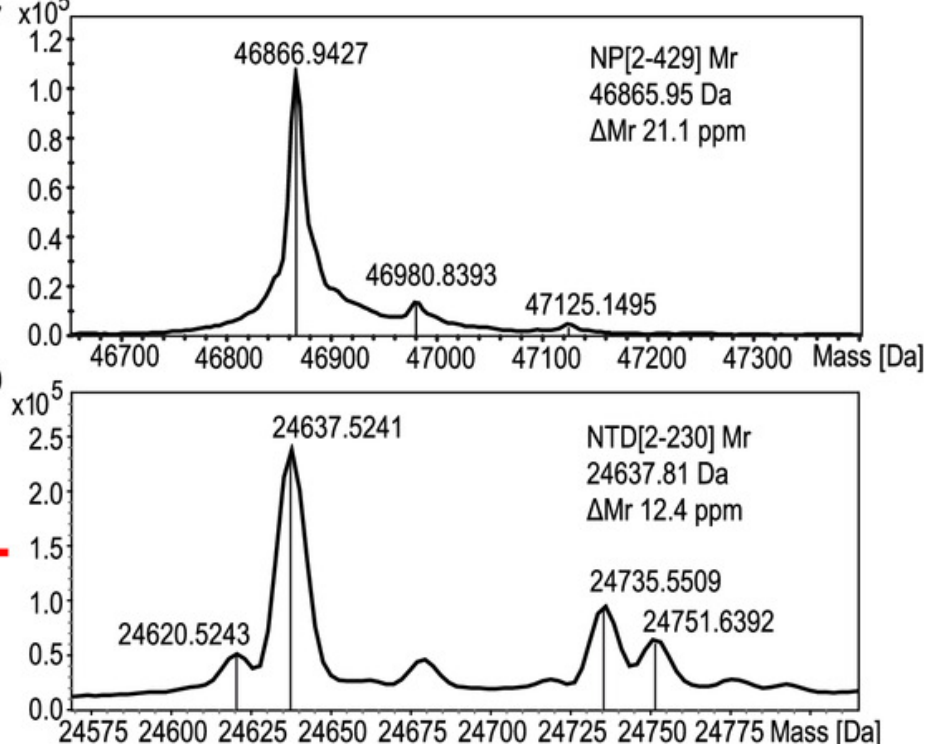

245752460024625246502467524700247252475024775 Mass [Da]

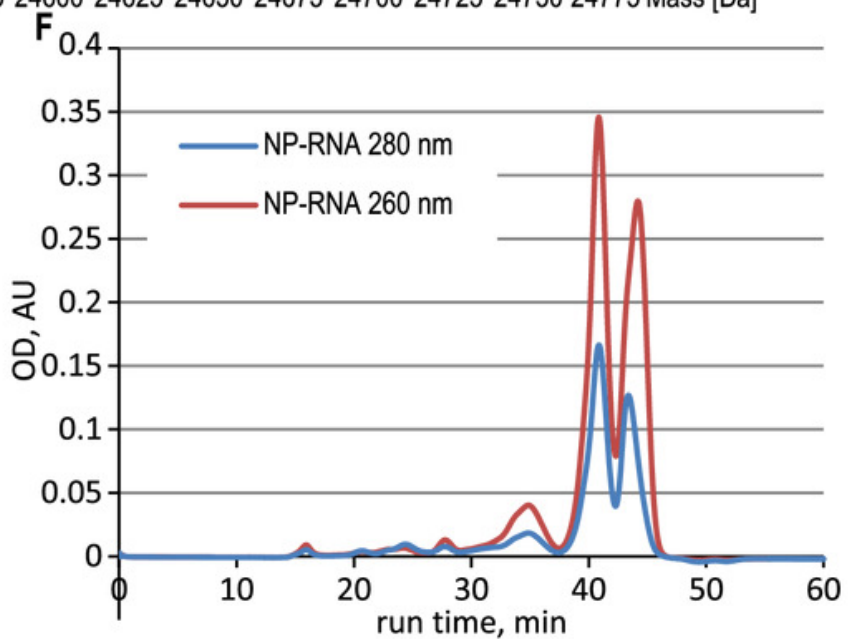


Figure 3

Figure 3 . Antigenic properties of the NP and NTD proteins.

(A) - Antibody capture ELISA with the pure NP and NP-RNA antigens, pooled PCR+ sera. (B) antibody capture ELISA with the pure NTD and NTD-RNA antigens, pooled PCR+ sera. (C) antibody capture ELISA with the pure NP and NP-RNA antigens, pooled pre-COVID sera. (D) Positivity indices of the control serum samples from the NIBSC sera panel, samples dilution 1600x; NEG - negative samples; POS - positive samples. (E) - same to (D), samples dilution 400x. Statistical analysis by the paired t-test for all panels, $n=3, *-p<0.05 ; * *-p<0.01$; $* * *-p<0.001$.

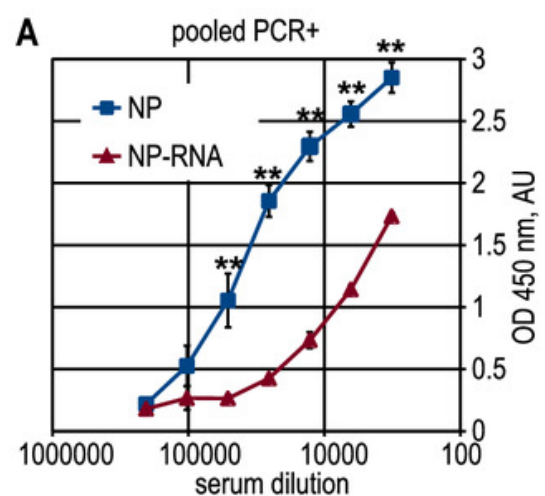

D
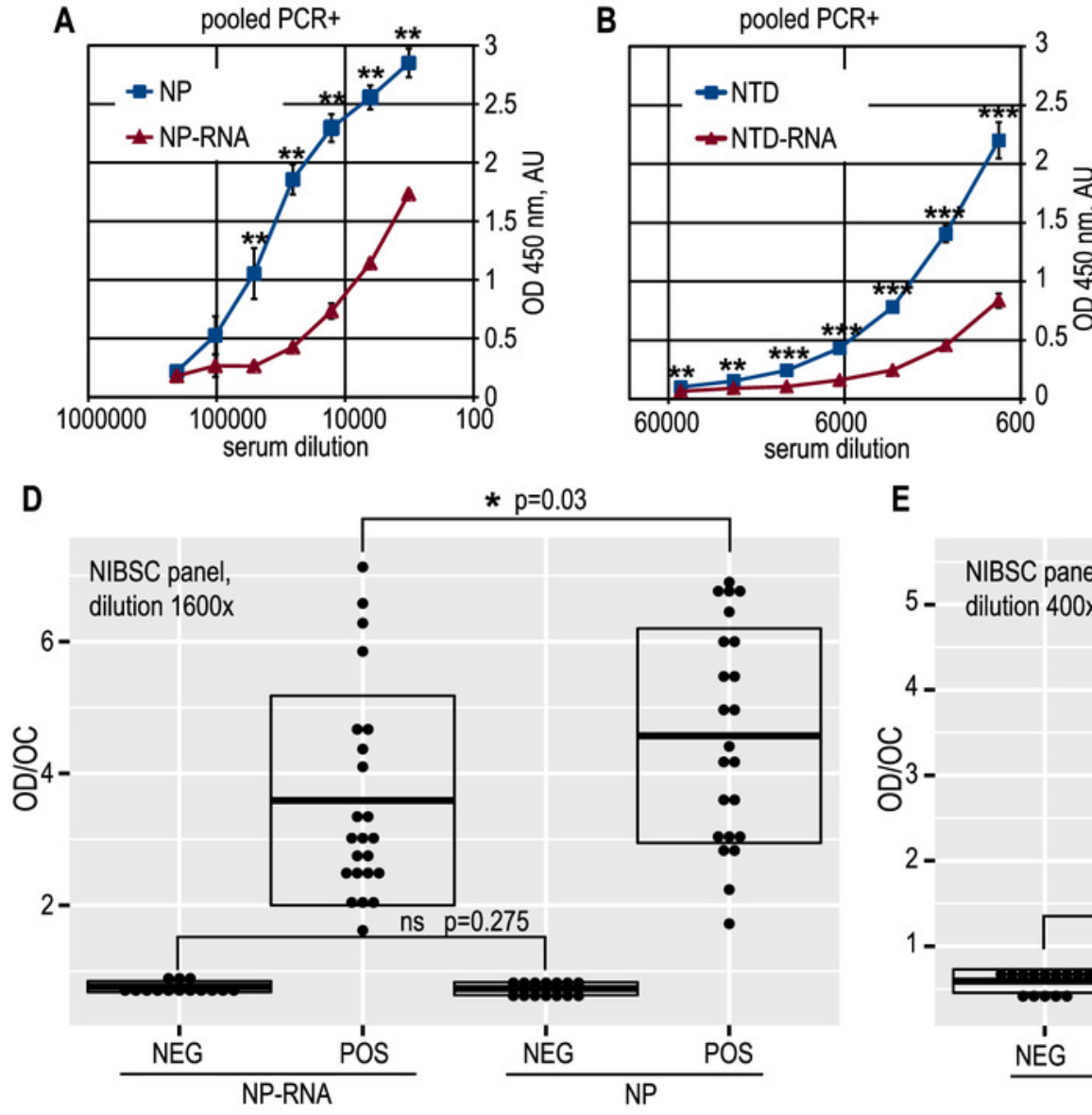

E
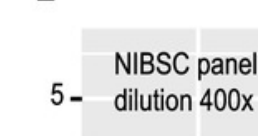

응
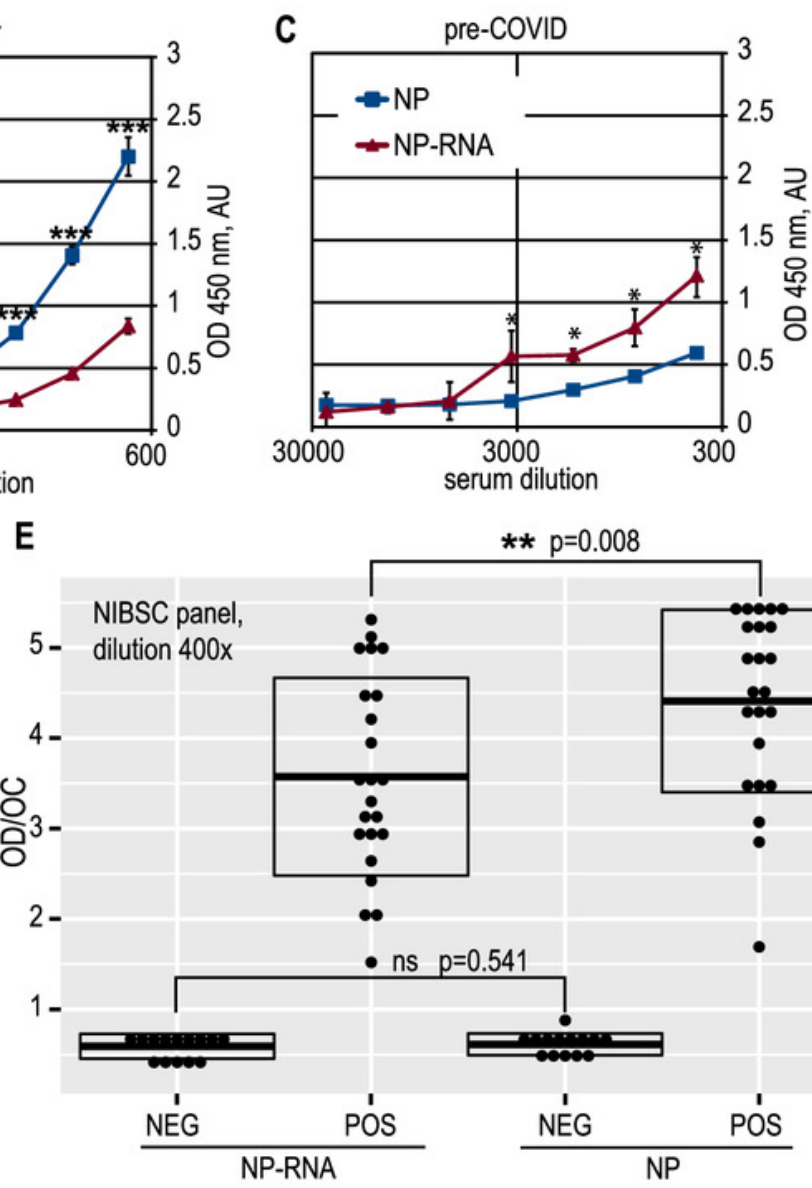

** $p=0.008$

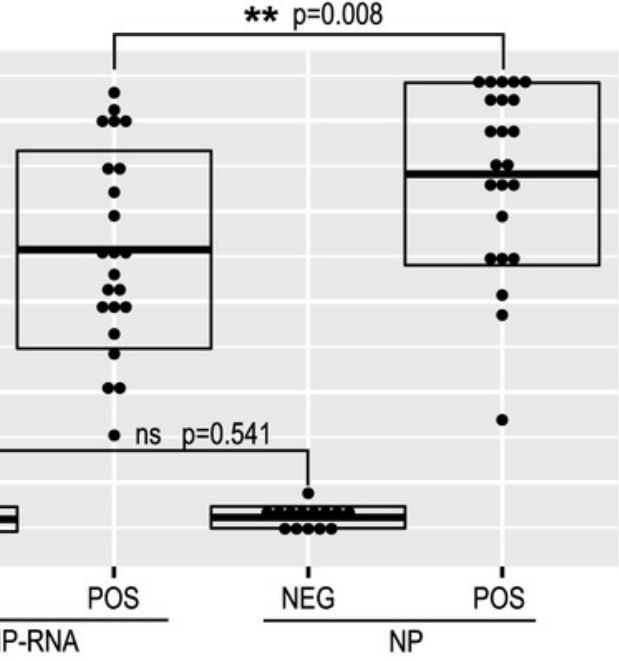




\section{Figure 4}

Correlation analysis of the NP ELISA and reference assays for NIBSC control sera samples.

The plot shows the Pearson coefficient that was used for the estimation, as well as the linear approximation. Pure NP and NP-RNA - experimentally performed assays, other data were taken from the NIBSC control sera panel description. S1, RBD, S1/S2 NP \#1, NP \#2 assay codes are described in detail in the Supporting Table 1. (A) - correlation analysis for the positive sample's subset; (B) - correlation analysis for all samples. 
A

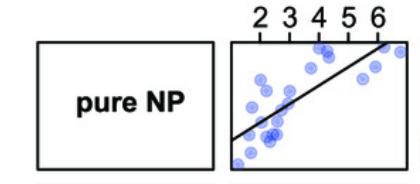

No 0.80
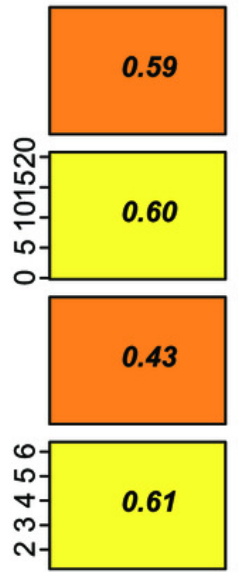

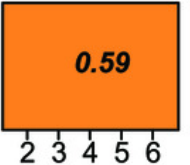

B
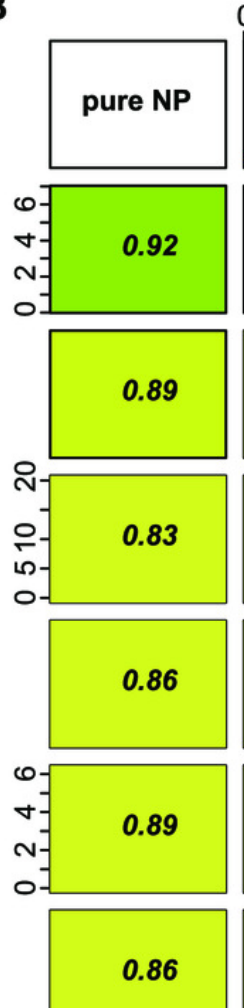

01233456
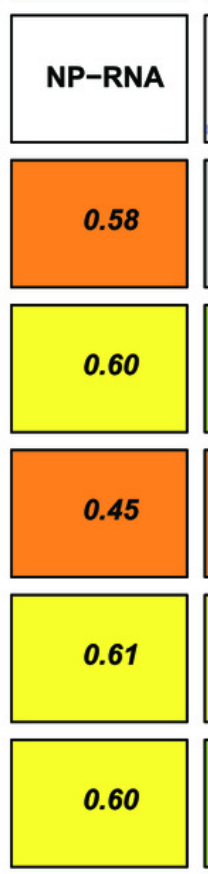

2345678

NIBSC panel, positive samples

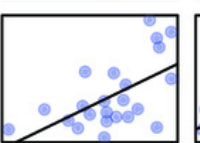

s1

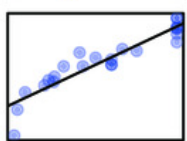

0.93

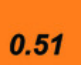

0.77

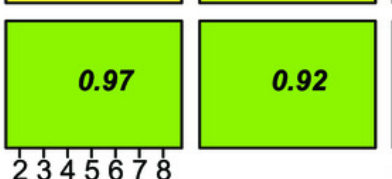

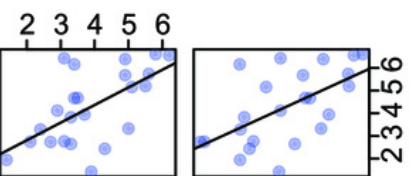
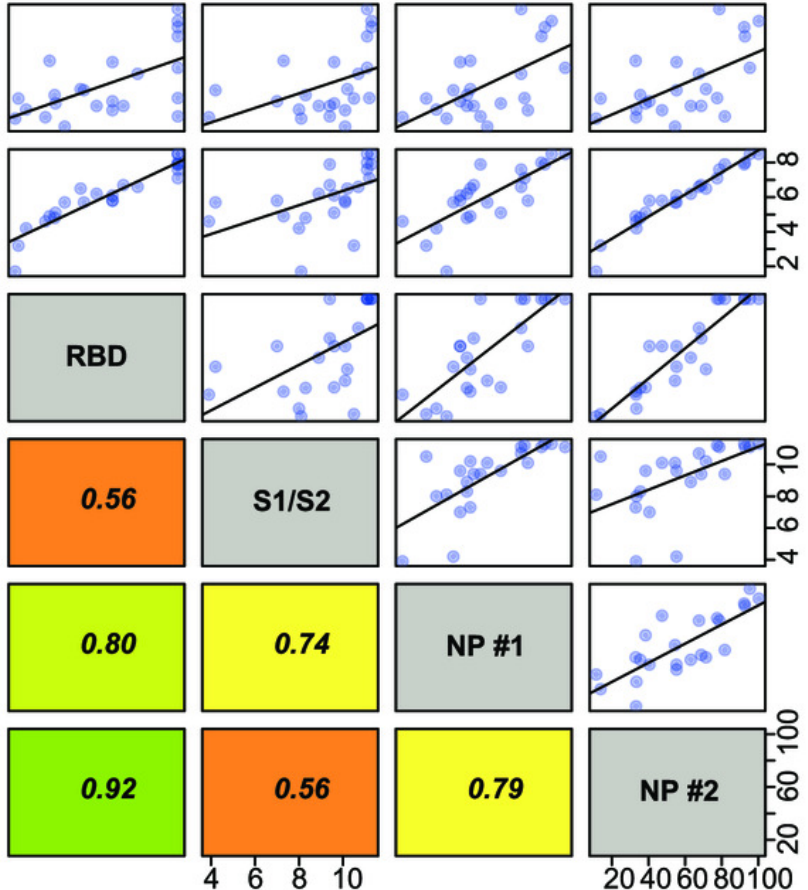

20406080100
$01234567 \quad 05101520$
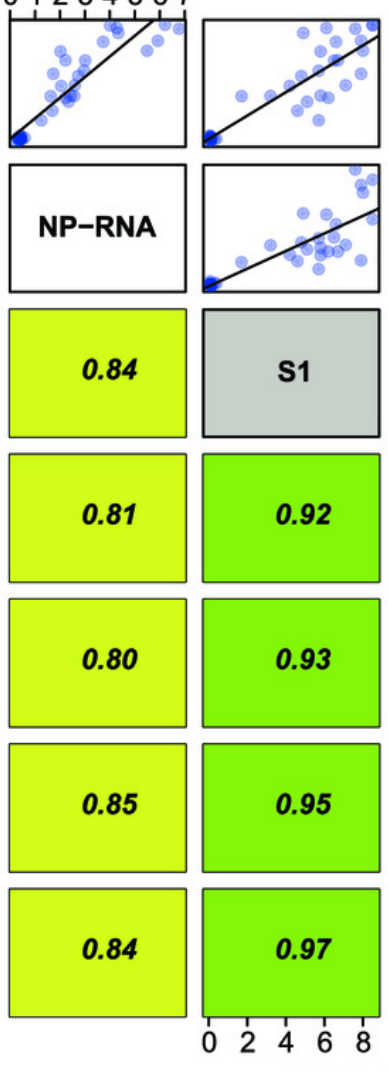

NIBSC panel, all samples

s1

0.92
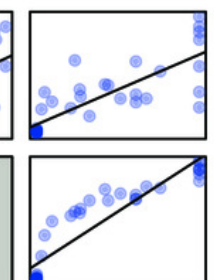

0.95

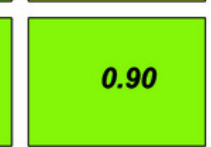

0123456
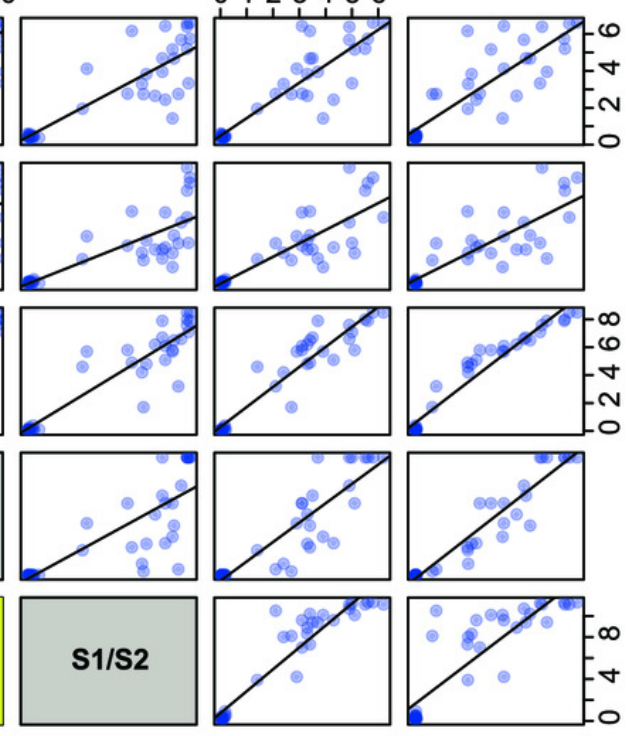

S1/S2
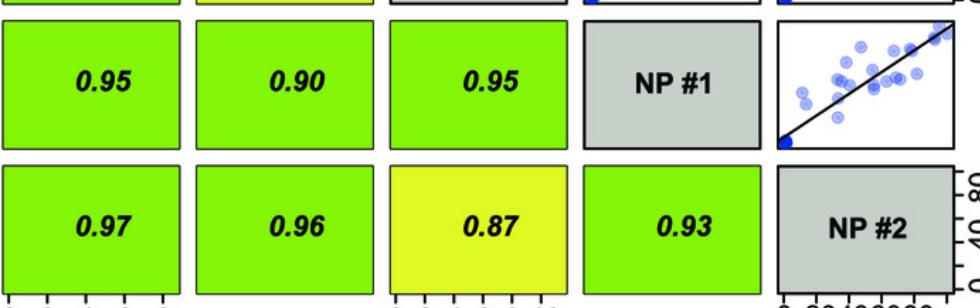

022468810

0.93

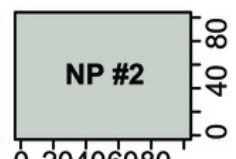

020406080 